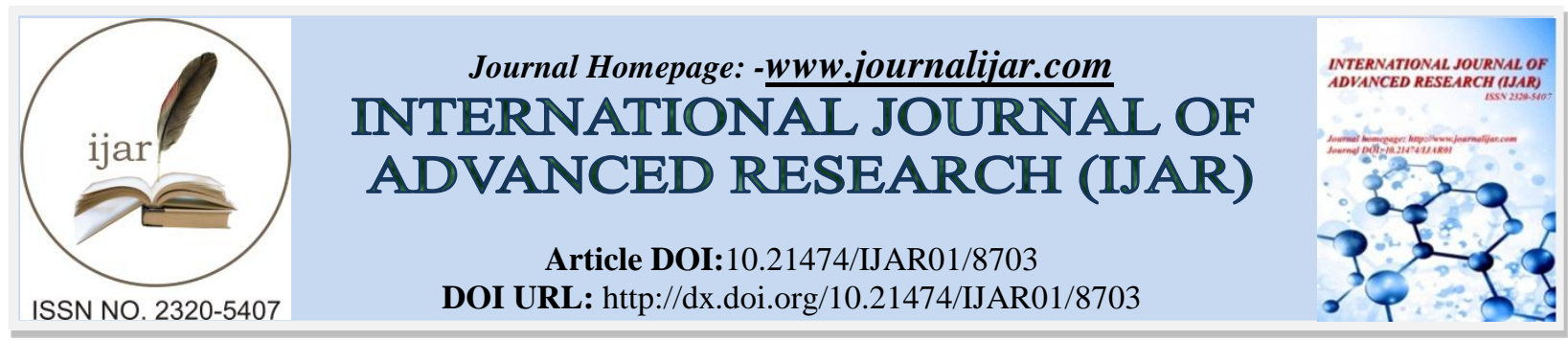

RESEARCH ARTICLE

\title{
SURVEY OF IMPRESSION MATERIALS AND TECHNIQUES USED FOR FIXED PARTIAL PROSTHESIS FABRICATION AMONG THE DENTAL PRACTITIONERS- A PILOT STUDY IN THE MAKKAH REGION OF SAUDI ARABIA.
}

\section{Dr. Karunakar Shetty ${ }^{1}$, Dr. Othman Wali ${ }^{2}$, Dr. Mohammed Shammas ${ }^{3}$, Dr. Narendra Basutkar ${ }^{4}$ and Dr. Rahul Sharma ${ }^{5}$.}

1. BDS, MDS (Prosthodontics), FICOI, Associate professor, Dentistry program, Ibn Sina National College of Medical sciences, Jeddah, Saudi Arabia.

2. BDS, MSc, Swedish board in Periodonology, Perio-Prosth; Fellowship from University of Florida, USA, Vice Dean of Dentistry program, Ibn Sina National College of Medical sciences, Jeddah, Saudi Arabia.

3. Associate professor, Dentistry program, Ibn Sina National College of Medical Sciences, Jeddah.

4. Assistant professor, Dentistry program, Ibn Sina National College of Medical sciences, Jeddah, Saudi Arabia.

5. Registrar Prosthodontics, Saudi Comission of Health specialities, Prestige dental centre, Hafar albatin, Saudi Arabia.

\section{Manuscript Info}

(..........................

Manuscript History

Received: 15 January 2019

Final Accepted: 17 February 2019

Published: March 2019

Key words:-

Fixed Dental Prosthesis, Impression materials, retraction cord, irreversible hydrocolloids, Gingival retraction, stock trays.

\section{Abstract}

The aim of this survey was to integrate impression techniques evolved all over the years for fixed partial dentures and to know the techniques and materials which are used in the present day by the practitioners. Material and methods: A questionnaire based survey was conducted among the dental practitioners of Makkah region of Saudi Arabia. . Ethical approval for the beginning of the study was obtained via Institutional Review Committee, Ibn Sina National College for Medical studies, Jeddah. A self-administered anonymous questionnaire was distributed to the participants. Data were analyzed by using SPSS 19 software. Results: Results shows that, majority of responses indicated use of irreversible hydrocolloid in stock metal tray for making the preliminary impression. $80 \%$ of them used retraction cord for gingival retraction and only few of them used elecrosurgery, lasers, rotary curettage and gingifoam. Maximum participants used hemostat along with retraction cord. Most of the participants used addition silicone with single mix heavy body with light body technique for making final impression and some of them used polyether. Conclusion: The ideal materials, technique, and armamentarium are required for the long-term success of the treatment for fixed dental prosthesis. Also, if the ideal procedure is not followed, it will lead to a compromised fit of the final prosthesis and failure of the treatment.

Copy Right, IJAR, 2019,. All rights reserved.
Corresponding Author:-Dr. Karunakar Shetty. Address:-BDS, MDS (Prosthodontics), FICOI, Associate professor,Dentistry program, Ibn Sina National College of Medical Sciences, Jeddah, Saudi Arabia. 


\section{Introduction:-}

Improvement of oral health and quality of life is the main goal of contemporary dentistry, since, it has been considered as an important part of patient's well-being. Eliminating oral pain and the problems connected to chewing and speech, as well as the improvement of aesthetics contributes to the improvement of oral health [1].

Tooth loss can have a negative impact on facial appearance, speech, and mastication. The replacement of missing teeth by appropriately designed prostheses is in demand, and is required to maintain good health and a normal life. There are several modalities of treatment for rehabilitation of partially edentulous patients. These include implant supported prostheses, teeth-supported bridges, and removable partial dentures (RPDs). However, some options such as dental implants can be difficult to implement due to general and/or oral limitations, financial issues, and patient preferences [2]. Resin-bonded fixed partial denture (FPD) is a legitimate treatment choice for the substitution of missing teeth in conditions when the protection of the tooth structure is required or the prosthesis assumes a transitional part in the oral cavity [3]. In spite of their inconveniences, for example, more regular rates of deboning than traditionally luted bridges, resin bonded FPDs have favorable circumstances, for example, an minimally invasive preparation, diminished cost and great patient acknowledgment [4]. Fixed prosthodontics is the area of prosthodontics concentrated on for all fixed dental prostheses. Such dental restorations efforts likewise alluded to as indirect restorations, incorporate crowns, bridges (fixed dentures), inlays, onlays and veneers.

Prosthodontics, as a specialty, has evolved abundantly in past few years. Materials and technological advances keep changing the face of every field every day. Twentieth century witnessed remarkable changes with regard to human longevity worldwide, and the twenty-first century is set to carry forward the gains in longevity further, both in the developing word and the developed world [1]. Various impression materials and techniques came into use since ages for fixed partial dentures, and all of them have some advantages and disadvantages and are suitable for specific conditions. This study used a questionnaire-based survey to assess and know the impression materials and techniques for fixed partial dentures that are being followed by the practitioners of India.

Polyvinyl siloxane impression materials are extremely popular because of their combination of excellent physical property, handling characteristics and dimensional stability [1]. Polyvinyl siloxane impression materials were introduced in 1970[2]. Such materials are reported to be the most stable when even thickness of 2 to $4 \mathrm{~mm}$ achieved with an acrylic custom made impression tray. Finally, making a custom tray is time consuming and expensive. An alternative approach is the use of stock trays. However, very little information concerning the reliability of this method exists. Several factors affect the success and durability of restorations. In general, the type of impression making, setting accuracy, material flow, temperature, humidity, mixing, disinfection and pouring time have effects on the final accuracy of the indirect restorations[5]. Supra-gingival margins are effective in periodontal health maintenance, but do not provide optimal aesthetics. So in most cases especially in aesthetics zone, the margin of the restoration is placed sub-gingivally. In tooth supported and implant supported fixed prosthesis, impression making requires accurate record of the prepared finish line area, especially in cases where the prepared finish line is located at same level of gingiva or sub-gingiva [1-3]. The gingival margin should be clean and available during impression making, allowing adequate flow of the impression material on it. Gingival sulcus must also be wide enough. Accurate impression is usually achieved with the sulcular width of 0.15 to $0.20 \mathrm{~mm}$. If the sulcus width is less than this value, impression material is unable to resist against the rupture and deformation, thereupon the impression marginal accuracy is reduced. The primary factor in defective record of marginal details is due to the inefficacy of the gingival displacement technique [6].

Prosthodontics as a specialty has evolved abundantly in the past few years. The materials and methods of fabricating fixed partial dentures keep evolving with more accuracy in day to day practice.[5] The success of fixed prosthodontics treatment is dependent on many factors such as selection of patients, diagnosis and treatment planning, impression making, cementation of prosthesis, communication with the dental laboratory, satisfaction of the patients, and proper follow-up.[1] As in general, most of the dental practitioners pay more attention to patient's flow, cost, and treatment time.[2] A mutual knowledge of the individual limitations plays a key role in developing a clinical judgment and a thorough knowledge of understanding the procedures. [3]

There are various techniques for making fixed partial denture (FPD) impressions.[7] These include the following: (1) The single copper band technique, (2) the monophase technique (in which an impression material of only 1 viscosity is used), (3) the single-step technique (in which impression materials of 2 viscosities are applied at the same time),or (4) the double-step technique (in which the impression is made in two steps, using material of different viscosity in each step). Livaditis G [7] compared the methods and effectiveness of traditional FPD 
impression system which includes the matrix impression system in relation to the registration of the finish lines and sulci of the tooth preparations, very less importance was given to the accuracy of the occlusal plane and impression techniques. The putty reline methods have become more popular among the dentists because of the ease of handling when compared to custom tray techniques. But due to the improper seating of the tray and compressibility of the putty material can lead to the variation in Interocclusal relations registration within the impression.[8] Although the bite registration method is commonly used to record and transfer the occlusal relations to the articulator,[9] minor variations in the occlusal plane occur due to the faulty impression procedure that are often unnoticed. This results in a variation in occlusal contacts while doing the clinical trials although it appears to be acceptable in the articulator. The ability to identify and analyze inaccurate impressions and to understand how to avoid them is key to successful restoration [6].

Only a few studies reported about impression materials and impression techniques used by the dental practitioners. Therefore, the purpose of this study was to do a comparative evaluation of impression materials and techniques used by the dental practitioners in Makkah region of Saudi Arabia.

\section{Materials and Methods:-}

This retrospective survey was conducted among dental practitioners who included both specialists and general practitioners in theMakkah region of Saudi Arabia.

Confidential questionnaires (Fig-1) was designed and adapted to suit the local context to assess the details of impression materials and techniques in fixed partial denture. Purpose of the study was explained to all the dental practitioners. The questionnaire had a total of 7 questions that were discussed with specialists in the dental field. Following changes to clarity and design, the questionnaire was piloted onto a small sample of colleagues and again followed feedback from them, the final questionnaire was agreed upon. The questionnaire was then sent to 200 private dental practitioners in Makkah region of Saudi Arabia personally and by mail. All dental practitioners were contacted regardless of age and assured of confidentiality. Data obtained was statistically analyzed using SPSS version 19.0 software.

\section{Results:-}

Characteristics of these study participants (TABLE1) revealed general practitioners comprising $61.1 \%$ and specialists with $38.9 \%$. About $88.8 \%$ of the participants were using irreversible hydrocolloid impression material for primary impression and only $8.3 \%$ were using other materials (TABLE 2).

Among the study participants, $77.7 \%$ were using complete arch impression trays for primary impression, $6.6 \%$ were using dual arch impression trays, whereas only 5.5\% were using sectional impression trays (TABLE 3).

$80 \%$ of them were using retraction cord for gingival retraction whereas; only $5 \%$ of them using elecrosurgery and $6.6 \%$ of them were using gingifoam. The study participants who were using retraction cord along with hemostat comprising $94.5 \%$ and plain were $5.5 \%$ (TABLE 4 ).

$67.8 \%$ were using addition silicone for making final impression, $12.2 \%$ were using condensation silicone whereas $12.2 \%$ were using polyether for making final impression for fixed dental prosthesis(TABLE 5).

$65 \%$ of the study participants were making final impression with single mix heavy body with light body, $16.6 \%$ of them were using single mix medium body with light body and $15 \%$ of them were using putty reline with light body with spacer (TABLE 6).

$48.3 \%$ of them using dental stone with high strength, $41.6 \%$ of them using dental stone, whereas only $3.5 \%$ were using dental plaster for pouring a cast (TABLE 7).

\section{Discussion:-}

Diagnostic impressions are essential steps for treatment planning in fixed partial denture. The diagnostic cast gives idea about occluso-cervical dimension of edentulous spaces, relative alignment and angulations of proposed abutment teeth, detailed analysis of the occlusal plane and occlusion [9-10]. The results of a survey show that most 
commonly used impression material for the diagnostic purpose is irreversible hydrocolloid (alginate). Irreversible hydrocolloid is popular, primarily because, of their low cost and ease of use compared to other impression materials. In fixed prosthodontics treatment planning; one of the challenging procedure is management of soft tissue, i.e.to maintain the normal appearance of healthy gingiva. Appropriate reversible gingival displacement and tissue management are required [8-11], which facilitates making the final impression so it accurately records the prepared finish line and some unprepared tooth structure apical to the finish line. Caustic chemicals such as sulphuric acid can be effectively used for gingival retraction. Alternative paste system can be used in conjunction with direct pressures [11].

An elecrosurgery unit can be used for tissue removal before impression making, but disadvantages are mucosal necrosis and loss of osseous structure [13]. Also rotary curettage, lasers are useful in gingival retraction of soft tissue management.

Various impression materials are available for making impression of FPD. Amongst the hydrocolloid impression materials, laminate technique, i.e. agar alginate technique, is better than using agar or alginate individually. Agar will record the prepared teeth accurately and the remaining arch is recorded with alginate [12]. Elastomeric impression materials have excellent properties as impression materials. Advantages of polysulfide include a long working time; good tear strength, good flow before setting, good reproduction of surface detail, and high flexibility for easier removal around undercuts and lower cost compared to silicones and polyether. Disadvantage includes bad odor and the lead dioxide materials that stain clothes and it cannot be repoured [13]. Condensation silicones are clean, pleasant materials for the patient. They are highly elastic and the setting time can be controlled with the amount of accelerator. These materials tend to be inaccurate due to shrinkage on standing and should be poured within one hour. Disadvantage of condensation silicone is that, they are hydrophobic and requires a very dry field, and are difficult to pour in dental stone [8].

Polyvinyl siloxane also known as addition silicones has excellent physical properties and handling characteristics. It is dimensionally stable, can record and can be poured at the convenience of the operator. Addition silicone has the best elastic recovery of all available impression materials, does not stain clothing, and has pleasant colors and scents. The impression may be poured one week after making the impression and multiple pours are possible. Disadvantages are that, material is expensive twice the cost of polysulfide; it is more rigid than condensation silicone and difficult to remove around undercuts [14]. Polyether is least hydrophobic than all elastomers, have good dimensional stability. Disadvantage is that polyether is stiff, so undercut should be blocked. Irreversible hydrocolloid is most commonly used by general practitioners. But they are not accurate enough for fixed dental prosthesis impressions. Irreversible hydrocolloid tear easily, must be poured immediately after removal from the patient's mouth, have limited detail reproduction and they are dimensionally unstable. Elastic recovery value of 97.3\% for irreversible hydrocolloid indicates less elasticity and therefore less accuracy than agar hydrocolloids and silicone and polyether impression materials [15]. The compressive and tear strength increase with increasing rates of deformation. The limit of reproduction is also lower, indicating that less fine details will be obtained. It has higher permanent deformation upon stretching to pass over undercuts. Amongst the elastomeric impression technique, the single phase technique is faster and easier to use. Single mix materials have some advantage in that, as a result of shear thinning, they have low viscosities when mixed or syringed but higher viscosities when inserted in a tray. In multiple-mix technique two separate mixtures are required. Putty wash technique, when used properly, impression with accuracy more than that of multiple mix can be obtained [12]. Dimensional changes on setting can be compensated for by use of a double impression or putty wash technique. Thickness of 1-2 $\mathrm{mm}$ is most important manipulative variables with this impression materials, survey results showed that, practitioners pour the cast within the range of 15 minutes one hour. Many of them send the impression to the laboratory. To prevent distortion, it is generally recommended that irreversible hydrocolloid, i.e. alginate impressions be poured immediately or within 15 minutes from the removal from patients mouth without wrapping in a wet paper towel. This is because; it is not possible to determine the amount of water absorbed or whether the right shape and dimensions of the oral tissues have been produced precisely [16].

Condensation silicone produce ethyl alcohol as a by-product of the setting reaction and evaporation of the alcohol results in distortion. The identical phenomenon occurs with polysulfide, where the by-product is water. These materials should be poured within one hour. Polyether can absorb water from the atmosphere and thus should be poured within one hour for maximum accuracy [15]. Addition silicone impression materials are stable because, there is no volatile by-product to the reaction and they do not give off or absorb water so it has better dimensional stability 
up to 720 hours (30 days). The provisional prosthesis should be fabricated to serve for limited period of time, have a biologic, mechanical and esthetic role. They may be fabricated in the dental office from any of several commercially available materials and by a number of practical methods. The success of fixed prosthodontics often depends on the care with which the interim restoration is designed and fabricated [16]. Avoiding provisional prosthesis can lead to marginal discrepancy and periodontal inflammation at the time of cementation of final prosthesis.[17] A survey shows that many practitioners prefer dental stone (Type3) as a material of choice because of its low cost. But literature shows that die stone i.e. high strength stones (Type 4) are most successful die materials because of their high strength and greater abrasion resistance [18]. Co-relation of the reason shortcoming observed by dental private practitioners is given in following table.

\section{Conclusion:-}

Irreversible hydrocolloid alginate is good for making diagnostic impression material for FPD treatment. Gingival retraction or soft tissue management should be followed. Elastomeric impression materials should be preferred over irreversible hydrocolloid (alginate) after tooth preparation. The cast should be poured preferably in dental clinics. Proper manufacturer's instructions should be followed about the recommended time for pouring of the cast for particular impression material to avoid distortion of impression. If impression is being sent to the laboratory; communication with the laboratory for the same is needed. The die stones should be preferred over dental stone.

Provisional restorations should be given after tooth preparation. Recall examinations are especially important for patients with fixed dental prosthesis and should be carried out by the dentist. Patient must understand the limitations of fixed prosthesis before treatment begins.

Table 1:-Specialitywise Distribution of Study Participants

\begin{tabular}{|l|l|l|}
\hline & $\mathrm{N}$ & $\%$ \\
\hline GENERAL CLINICAL PRACTICE & 110 & 61.1 \\
\hline SPECIALISTS & 70 & 38.9 \\
\hline TOTAL & 180 & 100 \\
\hline
\end{tabular}

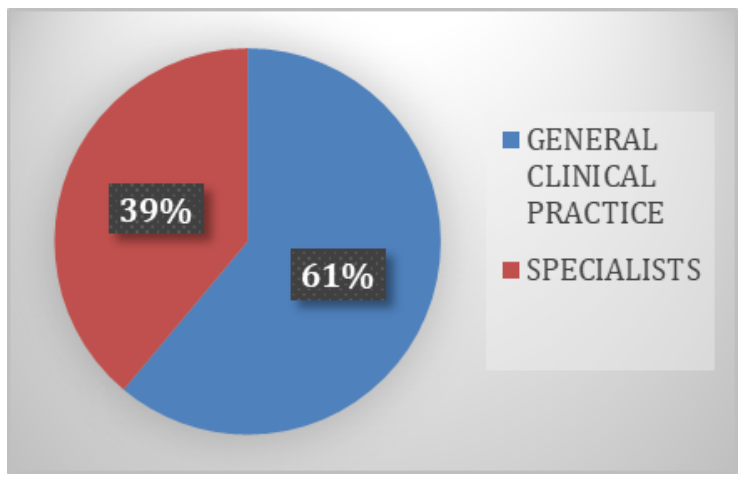

Table 2:-Distribution Of Study Participants Based On The Type Of Material Used For Recording Impression

\begin{tabular}{|l|l|l|}
\hline & $\mathrm{N}$ & $\%$ \\
\hline $\begin{array}{l}\text { IRREVERSIBLE } \\
\text { HYDROCOLLOID }\end{array}$ & 160 & 88.8 \\
\hline OTHER MATERIAL & 15 & 8.3 \\
\hline BOTH (A+B) & 5 & 2.9 \\
\hline
\end{tabular}




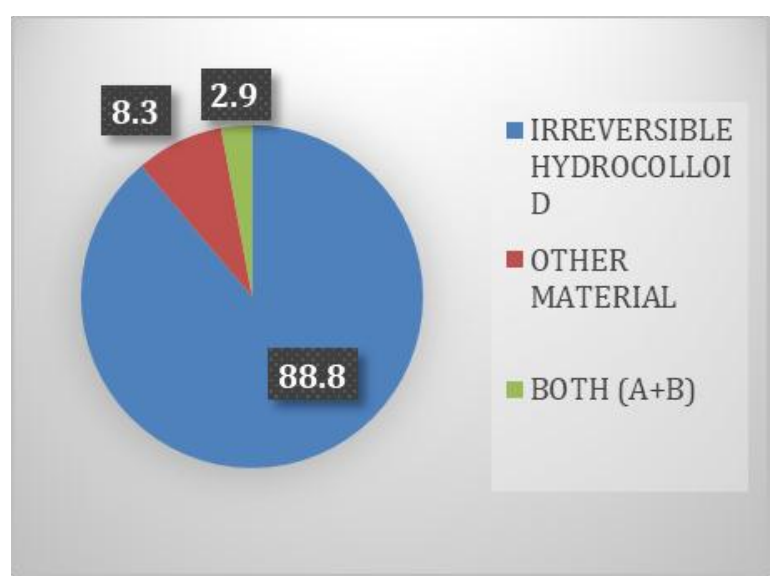

Table 3:-Distribution Of Study Participants Based On The Type Of Tray Used

\begin{tabular}{|l|l|l|}
\hline & $\mathrm{N}$ & $\%$ \\
\hline $\begin{array}{l}\text { DUAL ARCH IMPRESSION } \\
\text { TRAY }\end{array}$ & 12 & 6.6 \\
\hline $\begin{array}{l}\text { COMPLETE ARCH IMPRESSION } \\
\text { TRAY }\end{array}$ & 140 & 77.7 \\
\hline SECTIONAL IMPRESSION TRAY & 10 & 5.5 \\
\hline CUSTOM MADE & 9 & 5 \\
\hline COMBINATION (B+D) & 5 & 2.7 \\
\hline COMBINATION (B+C) & 4 & 2.5 \\
\hline
\end{tabular}

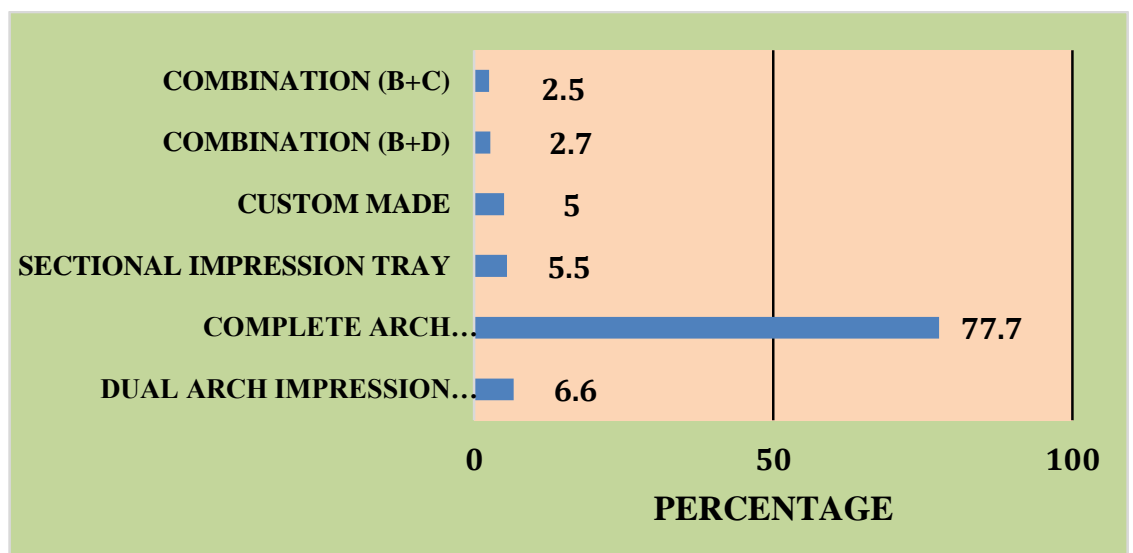

Table 4:-Distribution Of Study Participants Based On Practices For Gingival Retraction

\begin{tabular}{|l|l|l|}
\hline & N & $\%$ \\
\hline RETRACTION CORD & 144 & 80 \\
\hline ELECTROSURGERY & 9 & 5 \\
\hline LASER & 9 & 5 \\
\hline ROTARY CURETTAGE & 0 & 0 \\
\hline GINGI FOAM & 12 & 6.6 \\
\hline COMBINATION(A+C) & 6 & 3.4 \\
\hline
\end{tabular}




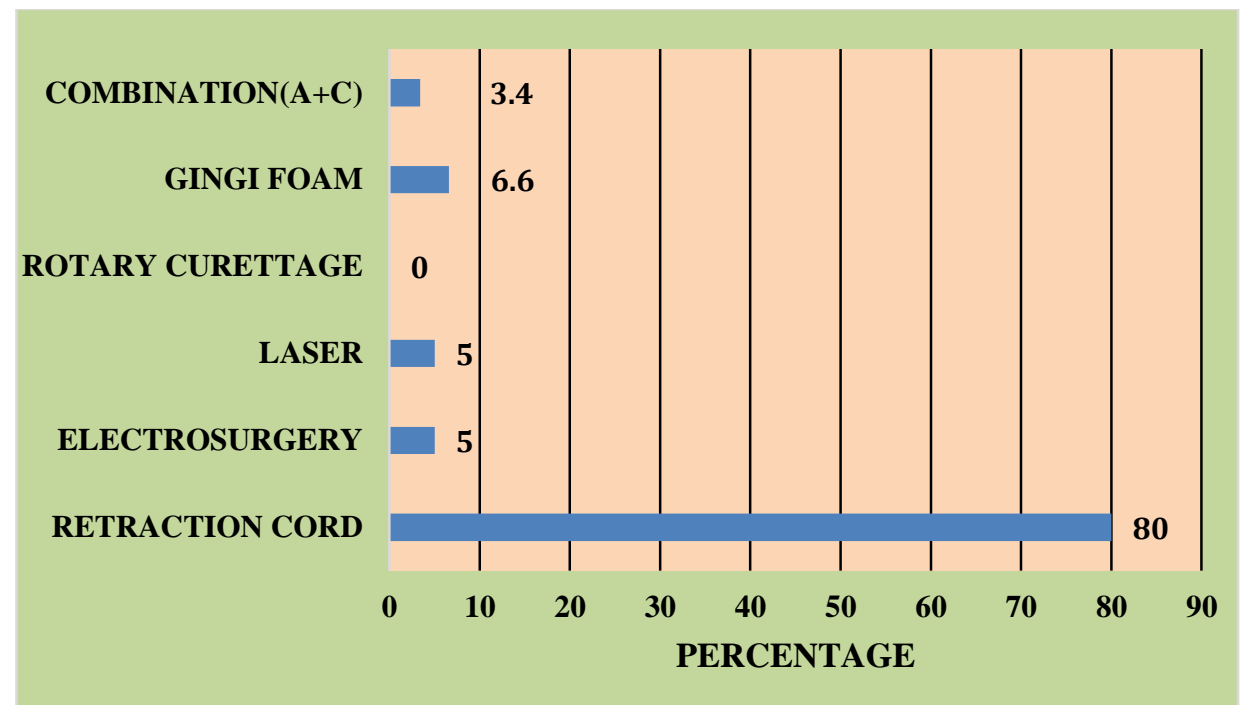

Table 5:-Distribution Of Study Participants Using Retraction Cord With Haemostat Or Without Haemostat

\begin{tabular}{|l|l|l|}
\hline & $\mathrm{N}$ & $\%$ \\
\hline PLAIN & 8 & 5.5 \\
\hline HAEMOSTAT & 138 & 94.5 \\
\hline
\end{tabular}

Table 6:-Distribution Of Study Participants Based On Their Choice Of Impression Material

\begin{tabular}{|l|l|l|}
\hline & N & $\%$ \\
\hline CONDENSATION SILICONE & 22 & 12.2 \\
\hline ADDITION SILICONE & 122 & 67.8 \\
\hline POLYETHER & 22 & 12.2 \\
\hline POLYSULFIDE & 0 & 0 \\
\hline ALGINATE & 0 & 0 \\
\hline COMBINATION (B+E) & 7 & 3.9 \\
\hline B+C & 7 & 3.9 \\
\hline
\end{tabular}




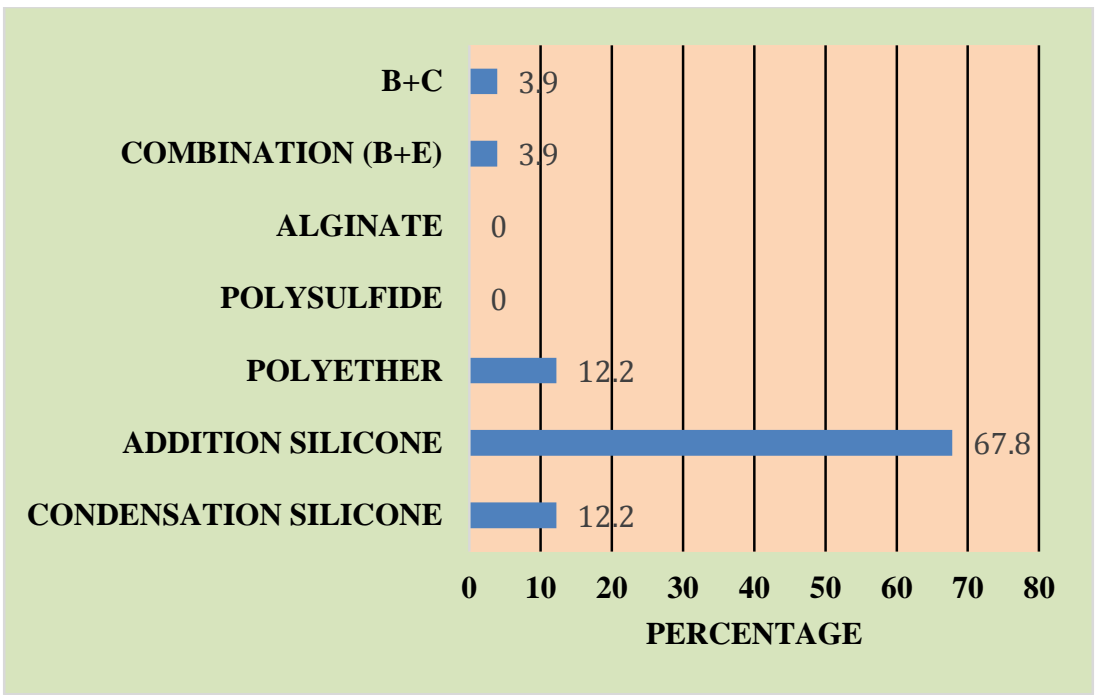

Table 7:-Distribution Of Study Participants Based On The Impression Technique Used

\begin{tabular}{|l|l|l|}
\hline & N & $\%$ \\
\hline $\begin{array}{l}\text { Single mix heavy body with light } \\
\text { body }\end{array}$ & 117 & 65 \\
\hline $\begin{array}{l}\text { Single mix medium body with light } \\
\text { body }\end{array}$ & 30 & 16.6 \\
\hline $\begin{array}{l}\text { Putty reline with light body with } \\
\text { spacer }\end{array}$ & 27 & 15 \\
\hline $\begin{array}{l}\text { Putty reline with light body without } \\
\text { spacer }\end{array}$ & 6 & 3.4 \\
\hline
\end{tabular}

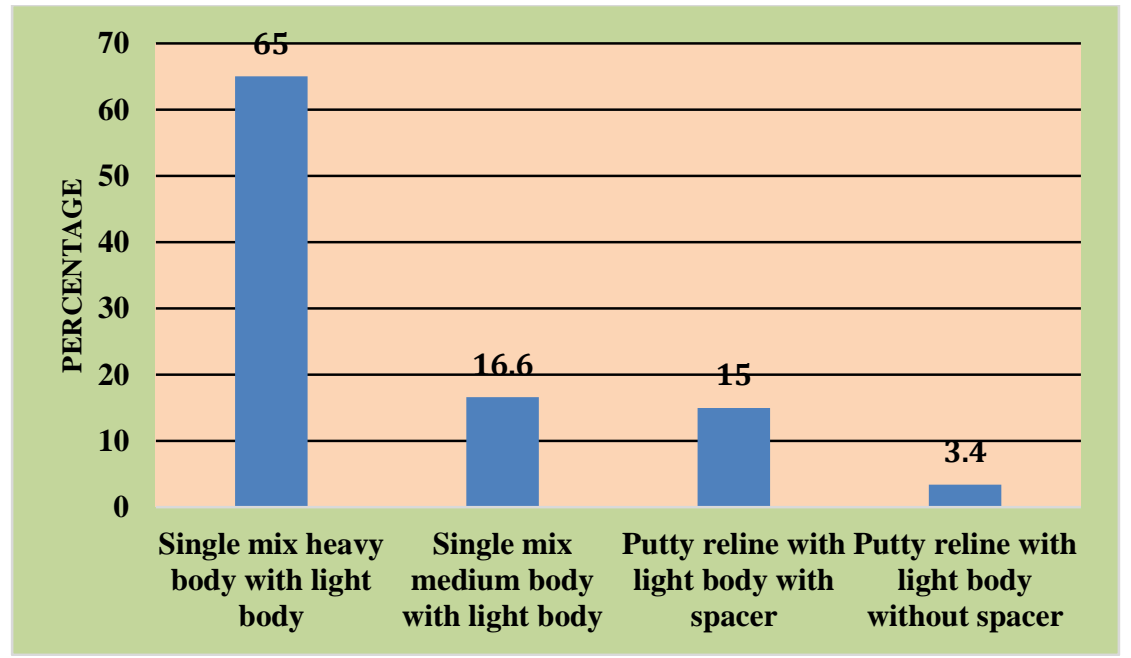

Table 8:-Distribution Of Study Participants Based On The Materials Used To Pour A Cast

\begin{tabular}{|l|l|l|}
\hline & $\mathrm{N}$ & $\%$ \\
\hline Dental plaster & 6 & 3.5 \\
\hline Dental stone & 75 & 41.6 \\
\hline Dental stone with high strength & 87 & 48.3 \\
\hline $\begin{array}{l}\text { Dental stone with high strength and } \\
\text { high expansion }\end{array}$ & 12 & 6.6 \\
\hline
\end{tabular}




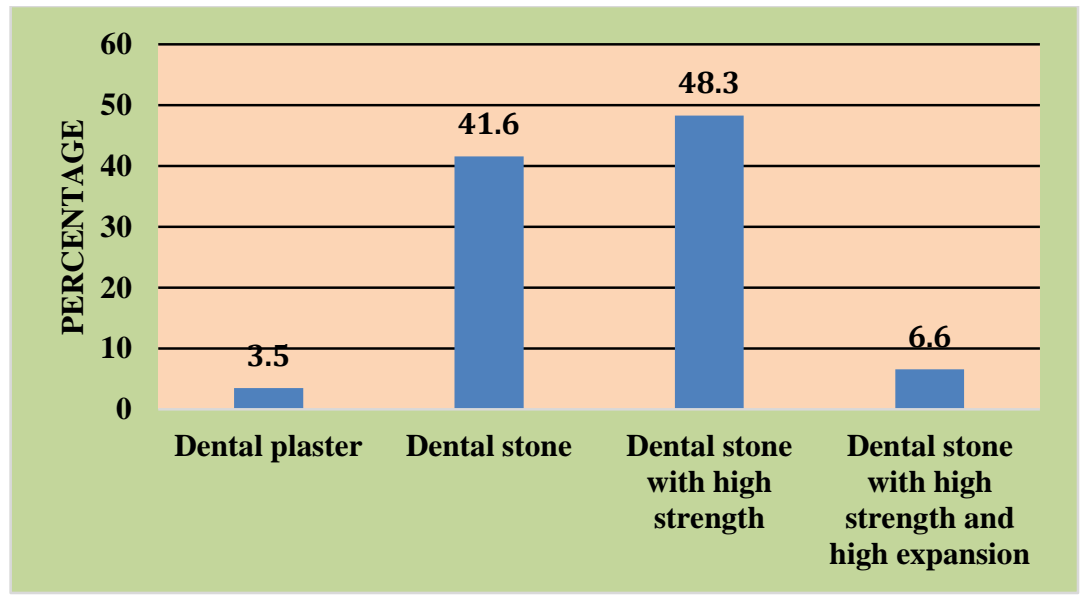

\section{Bibliography:-}

1. Coornaert J, Adriaens P, De boever J - Long-term clinical study of porcelain- fused-to-gold restorations. J prosthet dent 1984;51:338-41.

2. Amrita pritam, Nivedita mall - Estimation and evaluation of relative satisfaction levels in patients with fixed partial denture: a survey based original study, International Journal of medical and health research, 2017 ;3(9):73-76.

3. Adriana Cláudia lapria faria, Renata Cristina Silveira Rodrigues, Ana Paula Macedo, Maria dagloria Chiarello de Mattos, Ricardo Faria Ribeiro - Accuracy of stone casts obtained by different impression materials Braz Oral Res 2008 ; 22 (4): 293-8

4. Amar Bhochhibhoya, Binod Acharya,Samskar Bickram Rana, Rinu Sharma,1 Jenish Acharya, Brijesh Maskey Survey Of Current Materials And Impression Techniques For Complete Dentures Among Nepalese Prosthodontists Jcms 2018;14 (2 ):75-80

5. Amini Parviz1, Amin Rahpeyma, Maryam Hejazi - Comparative Analysis Of Dimensional Accuracy Of Two Types Of Silicone Impression Materials: Optosil And Elite-Hd. Jdmt 2017 ; 6(1) :1-6

6. Anshul Chugh, Aman Arora, Vijay Pratap Singh - Accuracy Of Different Putty- Wash Impression Techniques With Various Spacer Thickness International Journal Of Clinical Pediatric Dentistry 2012;5(1):33-38

7. Arvind Moldi, Vimal Gala, Shivakumar Puranik, Smita Karan, Sumit Deshpande, And Neelima Neela - Survey Of Impression Materials And Techniques In Fixed Partial Dentures Among The Practitioners In India ISRN Dentistry 2013: Article Id 430214, 2013

8. Ashish R. Jain - Gingival Retraction In Prosthodontics - A Review Journal Of Pharmacy Research 2017; 11(I2):1454- 1461

9. Amruta P. Jankar, Sanjay Nilawar, Swaroopkumar Magar, Puneet Mutneja -Impression Materials And Techniques Used And Followed For The Fixed Partial Denture Treatment By Private Dental Practitioners In Maharashtra State: A Questionnaire Study International J. Of Healthcare And Biomedical Research 2106 ; 4(3):83-92

10. Neda Al-Kaisy- A Survey Of Prosthodontics Techniques Applied By Dental Practitioners In Sulaimani City .J Bagh College Dentistry 2016 ; 28(3):22-29

11. Ashri Ny, Alrifaiy Mq, El-Metwally - The Effect of Gingival Retraction Cord On Periodontal Health Compared To Other Gingival Retraction Procedures: A Systematic Review. Periodon Prosthodon. 2016; 2:3.

12. Fahmida Binti Abd Rahman1, Ashish R. Jain- Knowledge, Attitude, And Practice Of Various Impression Techniques Available For Dental Implants Among Dental Students And Dental Practitioners - A Survey Drug Invention Today $2018 ; 10(5): 611-620$

13. Norman R. Wilhelmsen, Sigurd P. Ramfjord, John R .Blankenship - Effects Of Electrosurgery On The Gingival Attachment In Rhesus Monkeys J. Periodontol 47 (3) 160 -170

14. Nachum Samet, Michal Shohat,Alon Livny, And Ervin I. Weiss - A Clinical Evaluation Of Fixed Partial Denture Impressions J Prosthet Dent 2007; 94 (2) :112 - 117

15. Suprabha Rathee1, Beswaran, Maeswaran, Rprabhu4, Krgeetha, Gpkrishna, Jagadeshwari - A Comparison Of Dimensional Accuracy Of Addition Silicone Of Different Consistencies With Two Different Spacer Designs In-Vitro Study Jcdr 2014; 8(7): Zc38-Zc41 
16. Roopa Kundur Thippanna, Roseline Meshramkar1, Suresh Sajjan- A comparative study to evaluate different impression technique in relation to accuracy of the occlusal plane in fixed partial denture, Indian journal of oral sciences 2015; 6(1): 22-25

17. Izchak Barzilay, Effrat Habsha, Ms. Irene Tamblyn - Expa-Syl, A new form of tissue retraction that is quick painless Atraumatic and cost effective, The Canadian Journal Ofdental Technology 2001:18-24

18. Jeevitha Mani, Venkatesan N, Karthik V.C, Vidhu Antony- Systematic Review Of Gingival Retraction In Fixed Partial Denture Jpid 2018;1(3):188 -195. 